\title{
LA HABILITACIÓN EN EL ESPACIO PESQUERO-ARTESANAL CHILENO. PERSISTENCIAS Y VARIACIONES ESTRUCTURALES DE LA INTERMEDIACIÓN ECONÓMICA
}

\author{
ENABLEMENT IN THE ARTISANAL FISHING SPACE IN CHILE. STRUCTURAL \\ PERSISTENCE AND VARIATIONS IN ECONOMIC INTERMEDIATION
}

\author{
Gonzalo Saavedra Gallo ${ }^{1,2}$ y Magdalena Navarro Pacheco ${ }^{1,3}$
}

\begin{abstract}
Se presentan los resultados de una investigación etnográfica, complementada con textos de análisis socio-histórico, sobre los procesos de habilitación en economías costeras con predominio pesquero-artesanal en el centro-norte, sur y sur-austral de Chile. Se sostiene que la habilitación constituye una estructuración basal, cuyas expresiones espacio-temporales son variaciones de la intermediación económica fundadas en el endeudamiento. La configuración más nítida e institucionalizada de la habilitación la hemos retratado en las costas sur-australes, pero también es observable en otras latitudes litorales del país y en otras regiones latinoamericanas. Los principales antecedentes históricos para las zonas costeras provienen de documentos y trabajos realizados en la zona de Chiloé-Aisén en el marco de las migraciones de loberos, hacheros y mariscadores hacia el sur durante los siglos XIX y XX, instancias en donde las cuadrillas de trabajadores fueron provistas de insumos y víveres para las faenas y para sostener a sus familias durante la temporada. Los datos etnográficos incluyen testimonios obtenidos en Las Guaitecas, Calbuco, Valdivia y Los Vilos; el análisis revela las derivaciones y los cambios del modelo de habilitación, en tanto expresión persistente de la intermediación económica en las sociedades pesquero-artesanales contemporáneas.
\end{abstract}

Palabras claves: economías costeras, intermediarios, habilitación, pesca artesanal, deuda.

This work presents the results of an ethnographic study, supplemented by documentary sources, into enablement processes in coastal economies based largely on artisanal fishing in north-central, southern, and far southern Chile. Defined as the participation of an investor in the artisanal fisherman's activities by advancing capital for the purchase of consumables and equipment against a share of the proceeds, enablement (habilitación) is considered to be a basic form of structuring; its spatial-temporal expressions are variations of economic intermediation based on indebtedness. Although we have described the clearest and most strongly institutionalized form of enablement on the coast of the far south of Chile, it can also be observed in other latitudes along the coast of the country and in other parts of Latin America. The main historical background of the coastal regions comes from documents and research carried out in the area of Chiloé and Aisén regarding the migrations of sea-lion hunters, lumberjacks, and shellfish collectors to the south of Chile in the 19th and 20th centuries. In these cases, the gangs of workers were issued with consumables for their work and provisions to sustain their families during the season. The ethnographic data include witness reports obtained in Las Guaitecas Islands, Calbuco, Valdivia, and Los Vilos. The analysis reveals the origins of and changes in the enablement model as a persistent expression of economic intermediation in today's artisanal fishing partnerships.

Key words: Coastal economies, intermediaries, enablement, artisanal fishing, debt.

-¿Cuánto necesitan para hacer su revolución?-preguntó Pedro Páramo-. Tal vez yo pueda ayudarlos. -Dice bien aquí el señor, Perseverancio. No se te debía soltar la lengua. Necesitamos agenciarnos un rico pa que nos habilite, y qué mejor que el señor aquí presente (Pedro Páramo, Juan Rulfo 2015 [1955]).

$1 \quad$ Instituto de Estudios Antropológicos, Facultad de Filosofía y Humanidades, Universidad Austral de Chile, Campus Isla Teja, Valdivia, Chile.gonzalosaavedragallo@gmail.com; mnavarro@uach.cl

2 Centro de Investigación en Dinámica de Ecosistemas Marinos de Altas Latitudes (IDEAL), Santiago, Chile.

3 Programa de Doctorado en Antropología, Instituto de Arqueología y Antropología, Universidad Católica del NorteUniversidad de Tarapacá, San Pedro de Atacama-Arica, Chile.

Recibido: enero 2019. Aceptado: abril 2020.

http://dx.doi.org/10.4067/S0717-73562021005001702. Publicado en línea: 29-septiembre-2021. 
A mediados del año 2002 iniciamos una investigación etnográfica sobre sistemas pesqueroartesanales en el litoral de Aisén; en los años subsiguientes, y en este mismo ámbito de estudio, ampliamos nuestros registros hacia otras zonas costeras antropológicamente relevantes, entre ellas el mar interior de Chiloé y Reloncaví, la costa valdiviana y recientemente el litoral centronorte, comuna de Los Vilos. Estas investigaciones, atingentes a las dinámicas económico-identitarias de la pesca artesanal, nos permitieron conocer de primera fuente algunos condicionamientos simbólico-estructurales que modulan estos sistemas de reproducción de la vida material y sus lógicas de intercambio (Gudeman 2000; Polanyi 2009). Estos condicionamientos pueden expresarse en un modelo que, en la literatura sociohistórica latinoamericana y en nuestros propios registros etnográficos, se denomina "habilitación" (Chirif 2017, Illanes 1992; Villa 2014), referente al vínculo sustantivo y asimétrico entre habitantes locales que extraen recursos naturales y comerciantesintermediarios que los compran para distribuirlos en mercados nacionales y extranjeros. Este vínculo implica la provisión por adelantado de recursos materiales y/o monetarios, instituyendo una deuda entre las partes que siempre obliga su devolución. Debe advertirse que aun cuando la habilitación presupone una figura de intermediación, no sucede lo mismo a la inversa. Nuestros registros de campo indican que la habilitación ya era patente en las primeras décadas del siglo XX, sin embargo, y a partir de las evidencias bibliográficas, proponemos que esta dinámica relacional data al menos desde tiempos coloniales ${ }^{1}$. Y aunque los antecedentes que fundamentan tal afirmación son limitados, existen referentes latinoamericanos sobre condicionamientos de base colonial de la fuerza de trabajo que refrendan esta perspectiva. Por ejemplo, Chonchol (1994) describe las diversas formas que tuvieron los mecanismos de endeudamiento en México y Centroamérica durante los regímenes hacendales del siglo XIX y parte del XX. Los informes de Roger Casement, cónsul británico en Río de Janeiro, revelan cómo a principios del siglo $\mathrm{XX}$ los contratos basados en el adelanto fueron decisivos en los enclaves de explotación del caucho en la región del Putumayo en el noreste del Perú, persistiendo según Chirif (2017) hasta el día de hoy. La historiadora María Angélica Illanes (1992) retrata en el contexto de las explotaciones mineras del norte de Chile, en la misma época, dinámicas similares asociadas a préstamos y habilitaciones que constreñían fuertemente a los trabajadores. También en Chile, el entonces capitán de fragata Enrique Simpson observa y describe en sus bitácoras el sistema de enganche y habilitación que permitió explotar los bosques de ciprés en el litoral de Aisén por parte de empresarios afincados en Chiloé durante la segunda mitad de siglo XIX.

En nuestro planteamiento inicial la habilitación aparece como una estructura arquetípica que se encuentra en la base de los sistemas de intermediación actuales (en zonas litorales), aun cuando no sea predominante y localmente pueda admitir variaciones. Nos aproximamos al espacio pesquero-artesanal chileno centrándonos en el eje de la economía, no obstante, admitimos con igual centralidad la relevancia de sus condicionamientos histórico-culturales y ambientales. Ello explica que nuestro análisis resida en las dinámicas de extracción e intercambio que han desarrollado las comunidades locales en el presente. Sin embargo, bajo una perspectiva de historicidad estructural (Sahlins 1988), procuramos recurrir a variables temporales que mejoran la explicación observable en esa dimensión contemporánea, es decir, la habilitación como devenir, pero sobre todo como persistencia o, en algún sentido, como estructura de larga duración (Braudel 1983).

El análisis consta de cuatro apartados principales; en el primero realizamos una aproximación inicial al concepto de habilitación; en el segundo proponemos una perspectiva sobre ese concepto en el espacio costero latinoamericano, específicamente en economías de pesca artesanal; en el tercero presentamos una síntesis descriptiva de los sistemas pesquero-artesanales estudiados en Chile, las diversas expresiones de la habilitación y sus variantes bajo figuras de intermediación, especialmente en la segunda mitad del siglo XX (temporalidad asociada a la memoria oral de nuestros interlocutores); finalmente, en el cuarto discutimos los resultados explorando las manifestaciones históricas del modelo $\mathrm{y}$ ofrecemos nuestras principales conclusiones.

\section{Materiales y Método}

Nuestro material etnográfico deriva de investigaciones realizadas en Reloncaví, Chiloé y Aisén entre 2002-2016. Por entonces, en nuestras notas de campo era recurrente la habilitación, 
sobre todo en relatos de historia oral o en narrativas sobre el poblamiento insular. Aun así, el eje analítico principal está inscrito en información empírica producida recientemente, en el marco de un proyecto de investigación desarrollado entre 2017 y 2019 en las localidades costeras de Los Vilos, en la región de Coquimbo, Valdivia, en la región de Los Ríos, y Calbuco, en la región de Los Lagos (Figura 1). La selección de estos tres espacios estriba en su importancia en términos de desembarques regionales (relevantes a nivel nacional), en su marcada "tradición" pesquero artesanal y, por último, porque en los tres se observan con claridad al menos dos ejes de la vida económica problematizados en la investigación: la producción (extracción) y el intercambio mediado. Se realizaron 90 entrevistas y nueve grupos de conversación, de ese total 50 entrevistas y tres grupos de conversación corresponden a esta segunda etapa. Asimismo, hemos revisado algunas fuentes secundarias relevantes, en particular textos de interpretación histórica que nos han permitido contextualizar el material etnográfico. Las entrevistas y los grupos de conversación se organizaron siguiendo criterios muestrales cualitativos (Canales 2006) o estructurales (Montañés 2010), procurando alcanzar una saturación discursiva de los diferentes actores locales definidos como relevantes para la temática de investigación.

\section{El Concepto de Habilitación}

La habilitación comprende una dinámica de relaciones de poder entre diversos actores del espacio pesquero-artesanal. La entendemos como estructuración en el sentido literal del habitus, según lo propuesto por Bourdieu (1980, 2000), implicando en ello la configuración histórica, no consciente y práctica, de esas relaciones y por lo tanto susceptible de transformación aun cuando su permanencia es patente. Como sostiene Giménez (2002), los habitus suponen también la capacidad de invención y creatividad de los agentes, de tal manera que asociamos esa posibilidad de transformación a lo que Sahlins (1988) denominó la dialéctica estructura/acontecimiento; es decir, la estructura aunque persistente se expresa de formas distintas según la incidencia de los hechos y los procesos históricos. Habilitares proveere implica necesariamente a quien habilita y a quien es habilitado. En los casos observados y también de manera predominante en la literatura latinoamericana, la habilitación es un tipo de acuerdo que permite a determinados agentes de un espacio económico acceder a recursos naturales a través del trabajo de otros, para luego comerciarlos o distribuirlos en mercados -de proximidad o distantes- y obtener ganancias. Ese acuerdo está mediado por una deuda -pecuniaria, material y/o moral- que se torna persistente en el tiempo. Convengamos que en esta definición inicial nos situamos exclusivamente en el campo de la vida económica, sin perjuicio de que el concepto sea atingente a otros ámbitos de lo social.

Para el caso del sur-austral chileno, uno de los registros históricos que con mayor nitidez describe la estructura de habilitación es el que precisamente realiza el capitán Simpson al señalar que los empresarios de Chiloé adelantan a los hacheros "los géneros y golosinas que han menester, adeudándolos dentro de ciertos límites" y, "llegada la primavera, los obliga a salir a trabajar en el archipiélago en pago de la deuda, a un precio inadecuado", proveyendo también "víveres i aun licores durante las faenas" (Simpson 1872:85). La habilitación en la zona sur-austral ha sido descrita por el historiador Mateo Martinic (1986, 2005), quien además señala que solían firmarse "contratos de enganche", permitiendo a los armadores locales y extranjeros disponer de tripulaciones y fuerza de trabajo para efectuar las expediciones o faenas para la cacería de lobos marinos en Aisén y Magallanes, y luego la explotación de los bosques de ciprés en el litoral norte de Aisén. Es así que "convenido el enganche, se procedía a otorgar 'adelantos' a los tripulantes a cuentas de las futuras liquidaciones" (Martinic 1986:33). Un análisis sugerente y exhaustivo, en el contexto de la "colonización ovina" en Magallanes, ha sido realizado por Harambour (2019); también aquí encontramos, en el espacio marino, la figura del habilitador como agente explotador de la fuerza de trabajo indígena. Ambos autores destacan las suculentas ganancias que, por ejemplo, en el caso de las pieles de lobo marino, permitieron las habilitaciones.

La investigación de Illanes en el norte minero también consigna la firma de acuerdos. Denominados "contratos de habilitación", dotaron de una formalidad simbólica a un sistema de préstamos basado en adelantos (mercaderías o dinero) que debían ser devueltos en minerales y sujetos a cálculos de interés altamente beneficiosos para los acreedores; en palabras de la autora "lo básico de la habilitación era la sujeción del productor y sus productos al acreedor" (Illanes 1992:44). En rigor, como hemos subrayado, se trataba de un acuerdo sustentado en una deuda. Convengamos que para Illanes ese endeudamiento es, en lo medular, 


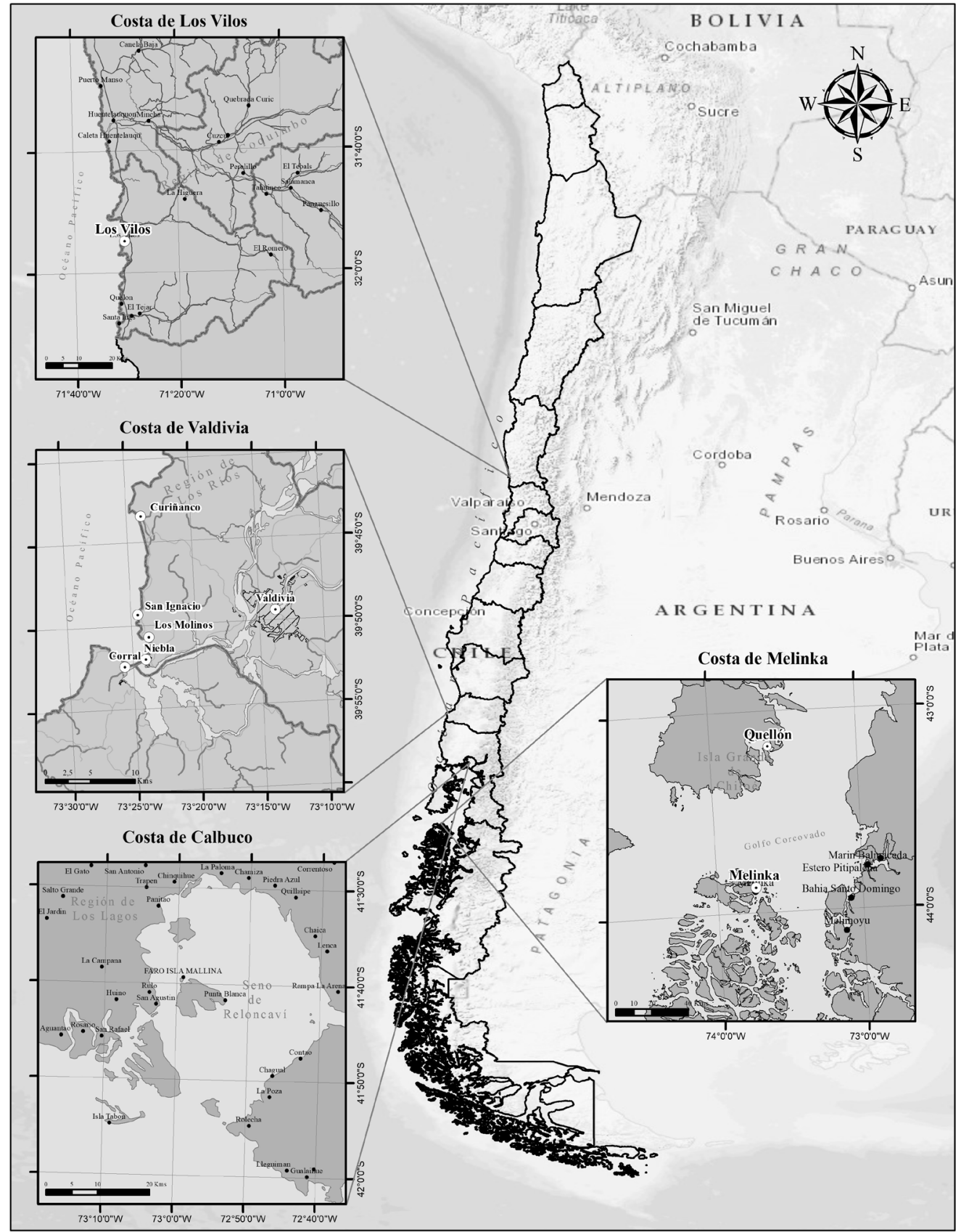

Figura 1. Mapa espacio pesquero-artesanal chileno. Elaborado por Zamir Bugueño

Map of the artisanal fishing space in Chile. Prepared by Zamir Bugueño.

analizado como un vector objetivo e institucionalizado de explotación de la fuerza de trabajo.

El antropólogo Alberto Chirif $(2012,2017)$ ha investigado y definido la habilitación en el contexto de la explotación de los pueblos indígenas en el Perú. Chirif ha evidenciado la persistencia estructural de esta dinámica societal, cristalizando relaciones desiguales que incluso en el siglo XX tomaron formas de esclavitud moderna al instituir que, ante la imposibilidad frecuente de saldar las deudas, los habilitados además de ser sometidos a castigos físicos, "podían ser transferidos como mercancía u ofrecidos como garantía para 
préstamos" (Chirif 2017). También aquí la firma del contrato es recurrente; es posible que el carácter particular y desfavorable de los mismos se deba a un marco institucional laxo y a un Estado más bien ausente.

La estructura de habilitación registrada en el suraustral chileno, al menos desde la segunda mitad del siglo XIX, y que también evidenciamos en registros etnográficos situados en el litoral de Los Vilos y de la región de Coquimbo en general, es persistente en determinados componentes basales (relaciones desiguales, dependencia económica, explotación de la fuerza de trabajo y de la naturaleza, adelantos y endeudamiento, sujeción moral) aun cuando se expresa de formas diversas a través del tiempo. Convengamos entonces que la habilitación, tal como la hemos observado en nuestro trabajo de campo, es un vínculo que articula a pescadores y comerciantes o empresarios en una relación de intercambio desigual, decisiva en el flujo monetario y de especies o recursos para la subsistencia material y, en último término, para el conjunto de las economías de pesca artesanal. Desde este punto de vista, sostenemos que la habilitación es un tipo de articulación de las economías localestradicionales (o basadas en prácticas consuetudinarias) al capitalismo (Comas d' Argemir 1997). El objeto de ese intercambio son los productos que los pescadores extraen del espacio marino-costero, pero el componente diferencial reside en la provisión por adelantado de esos recursos (dinero, insumos ${ }^{2}$ o víveres), puesto que aseguran, por una parte, la realización de la faena extractiva y, por otra, la entrega de esos productos a los comerciantes.

Se anticipa así una deuda que media la relación entre unos y otros, marcando una asimetría que será condicionante de toda esa dinámica relacional. La omnipresencia de esta deuda obliga, en cualquiera de sus formas, a devolver los recursos adelantados, pero también define el establecimiento de un compromiso -individual y colectivo-, de tal modo que esa obligación implica además un condicionamiento moral, cuyo arraigo parece revelarse también en la costumbre y en los hábitos (Wilk 2009). Aparece aquí, en su forma moderna, secular, mercantil y aparentemente des-subjetivada, la figura del don que hace un siglo investigase Mauss (2009) y tal vez una variación occidentalizada e híbrida de los "grandes hombres" que estudió Sahlins (1979) en Melanesia. Se advierten entonces dos aspectos cruciales: por una parte, la expresión sustantiva del vínculo en tanto "hecho social total" realizado en el comercio, pero bajo la forma de lo que el propio Sahlins denominó "reciprocidad negativa", es decir, aquella en donde prevalece la "ventaja utilitaria neta" (Sahlins 1977:213); y por otra parte, la configuración relacional del poder a partir del prestigio y la reputación de los habilitadores.

La referencia a un intercambio meramente material es analíticamente insuficiente, pues los condicionantes de la deuda trascienden ese ámbito instrumental e impregan las diversas relaciones sociales en los escenarios aquí reseñados. Las relaciones de habilitación están mediadas por componentes simbólicos y subjetivos, referidos a la representación que los pescadores (o taladores y cazadores en el caso del sur y sur-austral) tienen de los habilitadores o comerciantes y viceversa. Lo anterior presupone, siguiendo a Godelier (1990, 2014), que esas representaciones y esa configuración ideo-simbólica constituye parte indisociable de una matriz cultural que condiciona muy fuertemente las relaciones en el espacio productivo y comercial. En este marco, no puede sorprendernos que aspectos como la confianza, la amistad, la consanguinidad, el prestigio social o la vecindad sean realmente decisivos.

Pero, en otro plano, se revela un trasfondo que es fundamental para las sociedades pesquero-artesanales. La provisión por adelantado de insumos, víveres y dinero implica, simultánemente, la posibilidad de sostener la faena y la sustentación material -íntegra o parcial- de la casa del pescador durante su realización. Este segundo aspecto es significativo, pues se trata de la realización de la vida económica del hogar. Es lo que Polanyi (2009) definió como la reproducción social de la vida material de una comunidad, el eje fundamental de su existencia proyectada en el tiempo. También es atingente la tesis de Gudeman y Rivera (1990), para quienes las economías campesinas y pescadoras consisten en el despliegue de estrategias diferenciadas pero complementarias para asegurar la reproducción de "la base", la que debe entenderse como el fundamento material del espacio doméstico. La provisión de recursos transferidos en la habilitación apunta directamente a la realización económico-sustantiva de la comunidad costera.

\section{Una Impronta Colonial y su Persistencia en Otros Espacios Productivos}

Como ya anticipamos la habilitación no es exclusiva del espacio pesquero-artesanal, pues con distintas expresiones la encontramos en otros contextos. Cabe decir, sin embargo, que todos esos contextos comparten el sino del colonialismo, es decir, la institucionalización 
de relaciones desiguales, de dominación, basadas en la clase, la etnia o en la cultura. La consagración de estas relaciones, expresadas a través de la asimetría pescadores/ comerciantes o jornaleros/hacendados, se funda en lo que Mignolo (2003) denomina "la diferencia colonial", implicando la subordinación de los primeros respecto de los segundos.

Diversos estudios sobre la configuración de enclaves extractivistas, economías rurales y campesinas en Latinoamérica, consignan la importancia de los sistemas de préstamos y adelantos que luego derivan en figuras de endeudamiento persistentes en el tiempo; entre sus antecedentes cabe señalar los regímenes hacendales, por ejemplo, en Centroamérica y México (Chonchol 1994), Perú (Hobsbawn 2018:121-141) y también en Chile (Bengoa 2015:96-113). Esto no implica naturalmente una continuidad institucional lineal, al menos jurídica, entre sus estructuras societales y las formas modernas de explotación de la fuerza de trabajo en el campo o en las zonas costeras; no obstante, nos parece que es un aspecto al que debemos prestar atención.

Los contextos de las economías campesinas y de la ruralidad han cambiado significativamente. $\mathrm{Si}$ en la década del 1960 y 1970 se seguía debatiendo sobre la condición feudal o capitalista del latifundio (Kay 1977, 1995), en la actualidad se debate sobre las posibilidades reproductivas de esas economías en el marco de las nuevas condiciones del capitalismo en el espacio rural (De Grammont 2008; Salas y De la Fuente 2013). Esto ha implicado la reconfiguración de los territorios localizados en una dinámica de transnacionalización productiva, con predominio del empleo precario y una industrialización basada en la exportación de commodities, derivando en el deterioro de los socio-ecosistemas, todo en el marco de una neorregulación donde el rol del Estado se limita a gestionar el espacio institucional para el flujo de capitales (Otero 2013). Aun cuando han cambiado las condiciones del empleo rural, persisten determinadas dinámicas señoriales del "capitalismo hacendal" (Wallerstein 1998). Creemos no equivocarnos al suponer que las habilitaciones, siendo simultáneas al régimen de las haciendas en los siglos XIX y XX, persisten como expresiones relacionales que allí encuentran su profundidad histórico-estructural. Como lo describió Chonchol (1994:154-190), la relación entre hacendados o latifundistas y trabajadores jornaleros de todo tipo y origen estuvo mediada en esta época por los enganches, los adelantos y las habilitaciones. Debe añadirse, asimismo, que no solo de trató de "acuerdos" con los hacendados, sino también con grandes compañías que explotaron y comercilizaron los abundantes recursos naturales en los mercados externos.
Esto aparece ilustrado de modo sugerente en las investigaciones realizadas en las zonas de extracción de caucho en Colombia, en donde hacia el primer tercio del siglo XX "el sistema de endeude o avance" continuaba siendo la base de la explotación de la fuerza de trabajo (Santoyo 2010:344). Ciertamente, como se indica más arriba, lo propio sucedía en el Perú en la misma época; en este sentido, son reveladores los informes de Roger Casement -cónsul británico en Río de Janeiro- quien en 1910 fue encomendado para investigar las denuncias en contra de la empresa The Peruvian Amazon Co. (Chirif 2012), que utilizaba dicho sistema a objeto de asegurar fuerza trabajo en la explotación del caucho. Citemos a Casement: "En la mayor parte de la región amazónica donde florece el negocio del caucho prevalece un sistema de acuerdos que no es tolerado en la comunidades civilizadas. Puesto que afecta al hombre trabajador o individuo que vende su trabajo se denomina "peonaje" y es reprimido con drásticas medidas en algunas partes del Nuevo Mundo. Consiste en hacer que uno trabaje para uno haciéndole contraer una deuda y manteniéndolo allí. Para descargarse de su deuda la persona se ve forzada a trabajar para su acreedor bajo condiciones impuestas por este último" (Casement 2012 [1911]:51). Estas condiciones se mantendrían en las décadas subsiguientes, en parte porque "los 'enganchados' por el patrón mediante la habilitación" generaban "deudas que a la muerte del titular solían ser heredadas por los hijos" (Ortiz y Chirif 2010:137). Los autores sostienen que este sistema podía verse operando en diversas zonas del Perú hasta los años 1990.

En la región del Pacífico colombiano, "el endeude" ha sido fundamental en la progresiva sustitución de bosques nativos y espacios de agricultura familiar por plantaciones de palma africana (Escobar 2010). William Villa describe parte de esta dinámica, señalando su fuerte arraigo durante todo el siglo XX: "En las regiones boscosas... los comerciantes de maderas entregan a colonos el capital, la motosierra, el combustible y los víveres para que extraigan el producto y lo entreguen como pago del capital invertido", bajo este sistema "el productor no logra liberarse del comerciante y se convierte en su proveedor". [En el Pacífico] "el comercio de maderas se ha basado en este sistema desde mediados del siglo pasado" (Villa 2014:124).

A modo de corolario, subrayemos que el devenir de los sistemas agrarios y económico-rurales en América Latina, después de la Segunda Guerra Mundial, sienta sus bases en las formas de explotación de la tierra instituidas en el siglo XIX y principios del XX (Chonchol 1994; Kay 1995). En esos contextos ya son evidentes algunas 
expresiones del modelo de habilitación que actualmente podemos observar en las economías de pesca artesanal tanto en Chile como en otras latitudes latinoamericanas.

\section{Habilitación e intermediación en el espacio pesquero-artesanal latinoamericano}

En los últimos tres años, nuestro trabajo de campo se ha centrado en el registro y análisis de la intermediación comercial en las economías pesquero-artesanales. En ese marco, la figura del habilitador se nos presenta como una variante singular, aunque bastante extendida, del intermediario. La intermediación, definible como el enlace de dos procesos económicos a través de un tercer agente, constituye una figura recurrente en los sistemas pesqueroartesanales a nivel mundial (Pollnac 1995). Especialmente en escenarios contemporáneos, y por distintas razones estructurales, los intermediadores articulan distintos actores a mercados de acceso limitado para los pescadores. Pollnac sostiene que frecuentemente la intermediación no constituye un eslabón ajeno a las comunidades, cuestión constatada en nuestros registros de campo al evidenciar que muchos intermediarios-habilitadores pertenecen a las localidades y operan en variadas escalas de comercialización, incluso internacional.

En el contexto latinoamericano, sin utilizar necesariamente esta nomenclatura, el lugar de la habilitación en las economías costeras ha sido empíricamente documentado en diversas latitudes, y estas observaciones coinciden con nuestros registros. Entre los estudios relevantes que han explorado las dimensiones económicas de la pesca artesanal, cabría citar los compilados por Alcalá en México (2003) y en otras regiones latinoamericanas (Alcalá et al. 2011), los trabajos de Boivin, Rosato y Balbi en Argentina (2008), o Carneiro en Brasil (1986). En todos se advierten figuras relacionales propias de un sistema de intermediación-habilitación. Los registros de Carneiro, realizados en los años 1980, podrían considerarse tempranos en el campo de los estudios latinoamericanos sobre pesca artesanal, al observar que:

los mecanismos mas difundidos son los préstamos, el pago adelantado y el financiamiento de nuevos instrumentos de trabajo. Generalmente la incorporación de las innovaciones tecnológicas vienen a responder a ese interés ... A los armadores les interesa comprar botes y equipos y convencer a los pescadores para que trabajen para ellos (Carneiro 1986:34, la traducción es nuestra).
En la costa de Michoacán, México, Marín advierte una figura similar, pues "las organizaciones o los pescadores libres convienen de antemano que entregarán a un comprador en particular el total de sus capturas", implicando "un pacto con el intermediario", definido como un "patrón que les asegura los ingresos y les ayuda a solucionar problemas económicos por la vía de préstamos" (Marín 2003:53). Incluso, en el marco de un arraigado corporativismo estatal, Alcalá nos ofrece otro retrato revelador:

La paraestatal Productos Pesqueros Mexicanos (PROPEMEX), fundada por Echeverría en 1972, les hacía llegar combustible para los motores de las lanchas, algunas hieleras inmensas y hielo para abastecerlas, y a cambio recogía la captura una vez por semana (Alcalá 1999:87).

También en México, en Puerto Sisal, península de Yucatán, Perea observa que la relevancia de los comerciantes y/o permisionarios ${ }^{3}$ en la cadena económica es central, pues otorgan las condiciones para la extracción del recurso -como la lancha- a cambio de la entrega del producto. En la pesquería del pulpo los pescadores son atraídos por las temporadas de abundancia, siendo "empleados por los permisionarios para extraer pescado del mar y venderlo a los mismos empleadores". En este caso, tanto el equipo de trabajo como el capital pertenecen al permisionario, de modo que el pescador "no es libre", pues debe recurrir "a continuos préstamos de parte del permisionario", no obstante, "el pago muy comúnmente no puede ser cubierto y se comienza a acumular una deuda del pescador al permisionario" (Perea 2016:47).

En Argentina la intermediación bajo modalidades de habilitación ha sido latamente descrita por Fernando Balbi, quien analizó la producción y cadenas de valor en el delta del Río Paraná, provincia de Entre Ríos. El trabajo de campo fue desarrollado en 1989 y 1990, describiendo cómo "los acopiadores "entregaban insumos y "herramientas a personas que pescaban para ellos en condición de peones. Tales herramientas coincidían parcialmente con las que se empleaban hasta entonces en la zona... pero también... conllevaban aumentos en la productividad" (Balbi 2008:120-121).

Investigaciones realizadas en Ecuador y en Perú también evidencian literalmente las estructuras de habilitación. En el caso ecuatoriano se advierte que en los principales puertos del país esta figura opera: 
bajo el mecanismo de dependencia [que] consiste en que el comerciante provee de dinero al pescador para que pueda cubrir los costos que implica salir a pescar. Estos costos pueden estar relacionados con la compra de víveres, hielo, combustible, lo cual compromete el precio de la pesca cuando esta se realiza (Villao-Burgos et al. 2017:3).

Los autores denominan "habilitación" a este sistema y la definen como "un crédito de fácil acceso entregado a los pescadores por parte de los comerciantes" (VillaoBurgos et al. 2017:3).

En Perú el escenario relacional es prácticamente idéntico. A partir de un estudio realizado en 12 caletas, en 2009, Clemente concluye que "la habilitación o enganche consiste en que el comerciante mayorista presta dinero para financiar la salida a pescar" (Clemente 2009:11), añadiendo el adelanto de víveres, combustible $\mathrm{y}$ otros insumos, de modo que el comerciante impone los precios de compra. No obstante, en este caso también observamos una lectura menos frecuente; sostiene el autor que "en la habilitación el comerciante queda a merced del pescador/armador, si viene sin pesca, le quedarán debiendo y puede (en muchos casos) que tenga que seguir dándole dinero para que cubra los gastos de la siguiente salida" (2009:11). La perspectiva del autor reporta incluso otros matices, en particular diferenciando las implicaciones de la habilitación para el armador -quien encuentra en este sistema una modalidad favorable, casi exenta de riesgos- y para los pescadores -quienes de forma patente quedan sujetos a las condiciones estructurales del intercambio desigual. En una investigación reciente, también situada en la costa peruana, Galarza y Kámiche refrendan lo anterior, destacando su dimensión financiera en el primer eslabón de la cadena de valor, pues:

generalmente, son los habilitadores los que funcionan como un mecanismo de financiamiento y resuelven el problema de la falta de crédito en el sector pesquero artesanal; en específico, brindan dinero o materiales como hielo o petróleo, que permiten a los pescadores poder realizar la faena, pero a cambio de que les vendan toda su captura o parte de ella a un precio que los habilitadores fijan (Galarza y Kámiche 2015:52).

A diferencia de los registros históricos antes reseñados con Illanes en el norte, con Martinic en el suraustral y con Chirif en la zona de explotación de caucho en Perú, las autoras sostienen que se trata de una forma de créditos y préstamos informales -sin intereses y sin costos financieros-, pero que, tal como sucede en todos los casos, queda absolutamente condicionado por la deuda de habilitación. En efecto, "el costo del crédito está en el bajo precio que reciben por sus productos en el momento de la venta, y en la imposibilidad de buscar otros compradores, dado el compromiso adquirido con el habilitador" (Galarza y Kámiche 2015: 89-90).

\section{Expresiones históricas y contemporáneas de la habilitación en el espacio pesquero artesanal chileno}

Las sociedades litorales de importancia pesqueroartesanal se despliegan a lo largo de toda la costa chilena. Sus orígenes se remontan a pueblos prehispánicos que configuraron sistemas de vida basados en la pesca, la caza y la recolección de especies marinas (Llagostera 1993; Méndez y Jackson 2004; Quiroz y Sánchez 2004; Reyes et al. 2011), aunque también bordemarinas (Ther 2012) e intermareales (Skewes et al. 2012). Cabe sostener que, en sus orígenes, los antecedentes remotos de esos pueblos costeros presuponen estrategias adaptativas comunes o similares, geoespacialmente diferenciadas, pero siempre inscritas en particularidades ideo-materiales asociadas a cosmovisiones también diversas. Los procesos de colonización y modernización desencadenaron transformaciones sustantivas en esos modos de vida. Se podría admitir que el devenir poscolonial de los pueblos costeros, en Chile y en Latinoamérica, implicó una progresiva articulación a los mercados de distribución y consumo, primero a escala regional y nacional, para posteriormente consolidarse como economías proveedoras de materias primas de exportación. En este sentido, parece pertinente admitir la consideración de Morandé (1987), respecto de la monetarización e instrumentación de las estructuras societales en el neoliberalismo y su incidencia en la erosión de los valores tradicionales.

De acuerdo al Registro Pesquero Artesanal (RPA), para 2018, hay en Chile un total de 89.697 pescadores formalmente inscritos, de los cuales $24 \%$ son mujeres y el $76 \%$ son hombres (Servicio Nacional de Pesca [SERNAPESCA] 2019). Las regiones de mayor concentración -y con mayor índice de desembarquesson Los Lagos y Biobio, no obstante en toda la costa chilena hay asentamientos pesqueros de notable arraigo en dinámicas culturales localizadas. Precisamente este es un segundo rasgo que nos permite señalar la amplitud 
de los sistemas de pesca artesanal en Chile, inmersos en identidades de oficio, históricamente configuradas, pero diferenciados respecto de otras formas sociales de la vida económica.

También es relevante el encuadramiento normativo de la actividad, el que tiende a intensificarse desde la década de 1990 con la promulgación de la Ley General de Pesca y Acuicultura (Ley No18.892). Entre los principales dispositivos que regulan la actividad, considérense el propio RPA, las cuotas de captura, la regionalización (restringiendo la movilidad histórica de las flotas), el derecho (exclusivo) de la pesca artesanal de captura en las primeras 5 millas marinas, los diversos regímenes de acceso, en especial el establecimiento de las Áreas de Manejo y Explotación de Recursos Bentónicos (que limitan aun más la movilidad) ${ }^{4}$. En otra expresión de estas lógicas modernizantes, los pueblos pescadores -tradicionalmente organizados bajo sistemas de parentesco y redes de vecindad- pasaron progresivamente a organizarse en cooperativas (años 1960 y 1970), en asociaciones gremiales y sindicatos independientes (años 1980 en adelante), e incluso en microempresas (desde la década de 2000). Esta transmutación institucional se explica, en distintos registros, por la articulación de la vida económica de la pesca artesanal al Estado y al mercado.

Otro aspecto a considerar es la condición estructural del espacio pesquero-artesanal, persistente a lo largo del tiempo y que remite a las fuerzas económicas en distintas escalas de incidencia (nacional e internacional). Entendemos lo estructural, en este punto, como el conjunto de relaciones complejas que sitúan a las sociedades litorales en un entramado de intereses y flujos financieros que erosionan su capacidad auto-reproductiva (Cunningham y Bostock 2005). La expresión de esta condición es precisamente la articulación de la pesca artesanal al mercado, concretamente a los intermediarios (incluyendo formas contemporáneas de habilitación) y a las plantas de proceso, situadas en lugares estratégicos de las cadenas de valor 5 .

A continuación, expondremos un conjunto de relatos, testimonios y referencias de otras investigaciones que dan cuenta de diversas expresiones del modelo de habilitación, tal como ha sido vivido por familias de pescadores en diferentes latitudes del litoral chileno. Con particularidades evidentes, comprende variaciones históricas y territoriales de una estructuración común. Estas narrativas se refieren a acontecimientos y procesos cuya data se aproxima en el mejor de los casos a la mitad del siglo XX, de tal modo que la "reconstrucción" etnográfica del modelo tiene esa limitación. Las referencias y los relatos seleccionados han sido organizados a objeto de mostrar, en primer término, la lógica de la habilitación y sus variaciones, por ello no implican un orden cronológico estricto aunque tiende a representarse de acuerdo a su devenir temporal en el territorio. La habilitación favoreció el despliegue espacial de las cuadrillas de pescadores, articulando transversalmente hasta el día de hoy a un variado conjunto de prácticas extractivo-productivas y a una importante diversidad de recursos marinos, aunque en el caso del sur-austral también forestales y agrícolas. Asimismo, dada su dinámica socio-estructural, ha impulsado simultáneamente procesos de estratificación social bastante marcados en las comunidades y en el espacio pesquero-artesanal en general.

\section{Habilitación y movilidad espacial}

En las zonas litorales, al menos en Chile, la lógica de la habilitación, en los siglos XIX y principios del XX, ha sido descrita por investigadores en la zona sur-austral. A los citados trabajos de Martinic (1986, 2005), cabe añadir el análisis de Morales (2014), quien ofrece un retrato de las faenas de tala de ciprés en el eje ChiloéAisén, describiendo la articulación de los principales núcleos poblados de la Isla Grande con sus periferias. En el modelo reseñado por el autor se reconstruye una cadena de intermediaciones basadas en la habilitación de los hacheros, quienes reciben insumos y víveres por adelantado, viéndose forzados a las faenas de maderas nativas en la zona cordillerana y hacia el sur en las Guaitecas. Según Morales, los habilitadores son armadores de los pueblos chilotes, es decir, vecinos con mayor poder económico que actuaban como primeros intermediarios para luego entregar las maderas a comerciantes asentados en Ancud, quienes a su vez vendían a los grandes distribuidores del norte del país y que exportaban los dimensionados hacia Valparaíso y Caldera en Chile o El Callao en Perú. Desde un enfoque geo-histórico también cabe consignar el trabajo de Núñez et al. (2016), quienes toman como referencia las observaciones del capitán Simpson, para referendar la centralidad del adelanto y la deuda como dispositivo que, por una parte, fue decisivo para el enriquecimiento de los empresarios asentados en Chiloé y, por otra, permitió la configuración silenciosa del complejo espacio geográfico del litoral en Patagonia.

El siguiente testimonio corresponde a la mujer de un comerciante que a mediados de los años 1950 se instaló en Puerto Melinka. Las condiciones geoespaciales 
del sur-austral, pero también de otros litorales distantes de centros "urbanos", pudieron resultar propicias para consagrar el modelo de habilitación:

De diez hasta doce cuadrillas cholgueras... y él le traía víveres para alimentarles a todos. Uno le daba el material a su gente que trabajaba con máquinas escafandras, teníamos cinco, seis de esas máquinas y le dábamos a los buzos e iban a trabajar... (Elena, Melinka, septiembre 2002).

En el litoral de Coquimbo entendemos que la movilidad de los asentamientos temporales, denominados "varaderos" por los antiguos pescadores vileños, va marcando hitos a lo largo de toda la costa, hitos que terminarán siendorelevantesen laconstruccióneconómicocultural del espacio pesquero-artesanal, e incluso lo serán hastael día de hoy, aun con importantes restricciones de movilidad. El siguiente relato fue tomado del trabajo de Aranza Fuenzalida, el texto corresponde a la historia de vida de Raúl Tapia, pescador vileño nacido en 1919:

Por la década de 1920, llegaron a Los Vilos unos españoles que... tenían la idea de hacerse ricos y después devolverse a su tierra. Mi padre decía que habían venido a aprovecharse de nosotros... Tenían tres vaporcitos: el Bilbao, el Vizcaya y el San Pedro... y apenas llegaron, establecieron un sistema de trabajo con los pescadores de Los Vilos: el pescador que quería trabajar lo instalaban en una caleta y luego le compraban la producción. Donde quisiera quedarse el pescador lo acomodaban (Fuenzalida 2016:30).

Lo señalado por Raúl Tapia es corroborado en una entrevista realizada a Juan Carlos Delgado, buzo mariscador, pescador y escritor, quien define como funcionaba el sistema de habilitación -aunque en Los Vilos no tiene esa denominación- antes de la instauración de las actuales regulaciones administrativas. El relato revela la persistencia de aquella dinámica movilidad y habilitación todavía en los años 1980:

Entonces me decía el comerciante: Oye vamos a Puerto Oscuro, están sacando loco y hay re pocos materiales ¿vamos para allá? y yo converso con ustedes: ¿vámonos para Puerto Oscuro? -Vámonos, listo- ¿Quieres plata? -Sí, yo quiero plata- ¿Cuánto quieres? - tanto, y el comerciante: ya, hagamos la lista de víveres. Le hacías una lista de víveres y se iba, uno después estaba trabajando allá y calculaba: ¿tendrán plata en la casa?, y como el comerciante iba como cada dos días a buscar las cuestiones: Oye pasa para la casa a dejar plata -¿Cuánto es?tanto. Uno ya sabía más o menos lo que estaba ganando... (Los Vilos, abril 2018).

Nos parece relevante señalar que Delgado, en su libro "Mi vieja caleta..." (reeditado en 2018), ratifica esta descripción situándose algunos años antes:

Por aquellos tiempos Don Genaro Morales era el comerciante más poderoso de la zona, compraba locos hasta más o menos el año 1975, teniendo botes con materiales de buceo a lo largo de todos los varaderos y caletas, por el sur hasta Totoralillo y por el norte hasta Puerto Oscuro (Delgado 2018:78).

En la pesca de congrio y jaiba "yo me acuerdo que don Mirko llegaba todos los días en la mañana a buscarle la pesca, le traía algunos víveres, don Juan bajaba de vez en cuando a Los Vilos a pegarse unas copas y a traer algunos víveres... (Delgado 2018:110).

Esta práctica se mantuvo en Los Vilos en tiempos de "la fiebre del loco", en los años ochenta y noventa. En este caso los comerciantes se trasladaban con las cuadrillas de buzos hacia el sur, organizando faenas que se extendieron durante meses en lugares emblemáticos como Carelmapu, Puñihuil o Las Guaitecas. El testimonio que nos entrega Jorge, comerciante de locos en tiempos de la "fiebre", ilustra bien el fenómeno:

Entonces [después de la veda] dieron 15 días, y había que tener plata para financiar, traer los botes, el camión, alimento, todo para venirse para acá... Claro porque el pescador solo ¿Cómo venía, si tenía que financiarse? Porque tenía que dejar plata en la casa y aparte financiarse, entonces no podía dejar a la señora sin plata. Entonces yo me vine, me asocié con un amigo y nos vinimos para acá en camión, en el año 82. Eché 6 botes arriba del camión y me vine... Y en un bus se vino la gente, arrendamos un bus de Los Vilos (Calbuco, julio 2018). 
La habilitación favoreció el despliegue espacial de las cuadrillas de pescadores en diversas latitudes de la costa chilena. Lo que advertimos es una movilidad estrechamente vinculada a los intereses comerciales y/o empresariales de explotación de determinados recursos y pesquerías, todos de alto valor y demanda en los mercados, primero nacionales y, a partir de los años 1980, extranjeros. La realización de esos intereses ocurrió, predominantemente, estableciendo una deuda que mediaba las relaciones entre habilitadores y habilitados. Esa deuda es lo que aseguraba la reproducción del ciclo de habilitación-entrega del producto a los comerciantes, así como el despliegue espacial de las faenas (Figura 2).

\section{Habilitación e intercambio desigual}

El intercambio no solo es la condición inherente del modelo de habilitación, constituye además la expresión de esa desigualdad cristalizada en una deuda que trasciende un acuerdo o una temporada en particular. Esa deuda reproduce un tipo de relación social que define un lugar de subordinación muy preciso para los actores de la base social. La desigualdad estructural es patente en todos los relatos, también en los más actuales, que con frecuencia refieren a prácticas de explotación que se fueron reproduciendo y perpetuando en el tiempo. Coincide con el anterior, el testimonio de una mujer que entregó gran parte de su juventud al trabajo en las conserveras de Melinka: "Esos hombres... llevaban la habilitación pa' dos meses, pa' tres meses a la madera y dejaban habilitación pa' sus casas y pa' pagar esa habilitación pa' su casa y otra que llevaban ellos, no sacaban ni un peso... si querían comer tenían que volverse a encalillar en los patrones... [El hombre] se empezó a hacer rico con la gente pobre, claro, igual [antes] era pobre él" (Melinka, junio 2002). El relato pudo estar situado en las décadas de 1960 o 1970, pero lo que llama nuestra atención es su coincidencia con algunas observaciones de mediados del siglo XIX e inicios del XX (comentadas más arriba), en donde apreciamos que la contrata por habilitación bajo adversas condiciones ha sido recurrente.

Durante un viaje en lancha al canal Pérez sur en 2014 (archipiélago de Los Chonos), escuchamos el extenso relato que Héctor, buzo y patrón de nave, compartió con nosotros rememorando la vida de sus mayores:

... "mis padres y nuestros mayores trabajaron como esclavizados", lo primero que viene

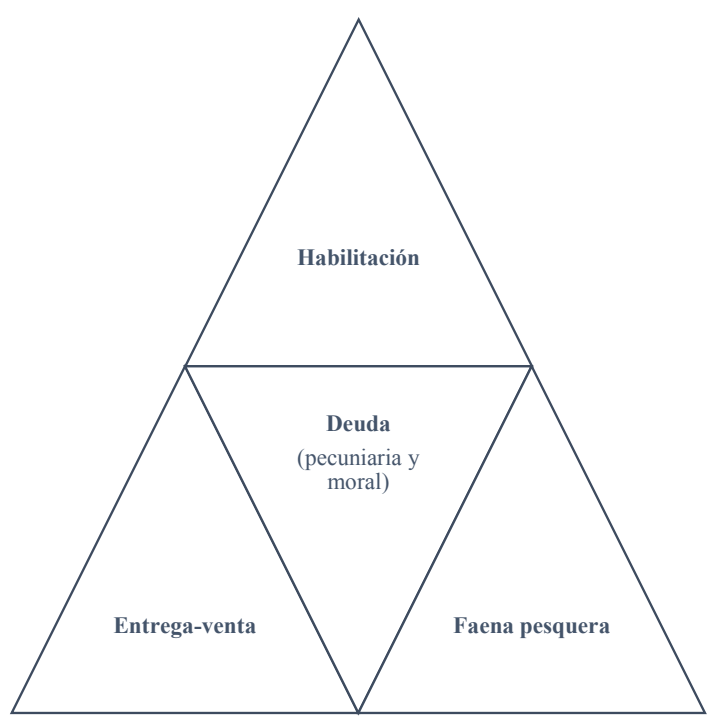

Figura 2. Esquema ciclo de habilitación en el espacio pesquero artesanal chileno.

Diagram of the enablement system in the artisanal fishing space in Chile.

a mi mente es precisamente lo descrito por Simpson hace un siglo y medio... Sus padres y sus mayores trabajaron en la década de los 40, 50 y 60 , tal vez en los años 70, es decir, casi un siglo después de los viajes hidrográficos de la corbeta Chacabuco... entonces el "sistema" parecía ser el mismo o muy similar al referido por el capitán Simpson: "Habilitadores se hacían llamar ellos", lo remarca tres veces en la conversación, nos comenta lo que en otras oportunidades ya observé: trabajaron con recursos, con víveres, que les dejaban tanto a la cuadrilla como a las familias que quedaban en tierra. Con cierto orgullo relata que ellos -él y su mujer- son la primera generación que logró salir de ese sistema, romper con la esclavitud que los obligaba con el habilitador (Diario de campo, canal Pérez sur, febrero 2014).

Las condiciones espaciales adversas, como ocurre en el litoral de Aisén (con distancias significativas de grandes centros de abastecimiento y consumo), si bien son importantes, no permiten explicar la persistencia de la habilitación. Esto, que en cierto modo también evidenciamos en Calbuco y en Los Vilos, es todavía 
más nítido en otros contextos de pesca artesanal. Por ejemplo, en condiciones de alta conectividad con un centro poblado, los pescadores de la costa valdiviana declaran que la provisión adelantada de combustible es crucial:

En el caso del pescado, llega el bote acá y le entrega al comerciante, al tipo que está acá. Si otro día llega otro vehículo y está pagando más, yo no le entrego... porque pierdo el combustible. Estaría obligado a ir a Valdivia a comprar y si no tengo los medios no puedo. Voy a perder un día de trabajo... Él nos trae el combustible, pero nosotros le tenemos que traer el pescado (Grupo de conversación, Los Molinos, octubre 2017).

Un caso similar a este, en particular por el emplazamiento espacial en el entorno urbano, ha sido recientemente descrito en Valparaíso -caleta El Membrillo-, en donde los comerciantes "han establecido un sistema de dependencia y control sobre los pescadores por medio del acceso a créditos y "compromisos" de entrega exclusiva hacia ellos (Gorgerino 2016:16).

Estos y otros testimonios, reseñados en el texto, revelan que los condicionantes de la habilitación son múltiples. No se trata solo de factores objetivos, propios de intercambio monetario o de bienes materiales, tampoco se trata solo de distancias espaciales o emplazamientos geográficos. Como veremos a continuación hay variables intersubjetivas y simbólico-estructurales que, tal como podría presuponerse a partir de las teorías del don y del intercambio (Mauss 2009; Godelier 1998; Sahlins 1979), son tan determinantes como las anteriores.

\section{Habilitación, confianza y estratificación del espacio pesquero-artesanal}

La radical apertura de la economía chilena, a mediados de los años 1980 (Ffrench-Davis 2002), derivó en un incremento de la demanda exportadora, en una creciente sobreexplotación de los recursos y en una cierta alineación de intereses entre exportadores y comerciantes locales, que hasta ese entonces distribuían en los mercados nacionales. En este contexto, en la escala territorial de las caletas, seguirán siendo los intermediarios los principales enlaces entre las comunidades de pescadores, las redes de distribución y los consumidores; y aunque el dinero comenzaría a prevalecer, la lógica de la habilitación (adelanto y endeudamiento) no desaparecería del todo en las relaciones pescadores/comerciantes. Así nos lo explica Jorge cuando preguntamos por los acuerdos que hoy median los tratos: "Yo en mi caso particular lo que hago es de palabra nomás, si ellos me piden que les compre algo, yo se los compro... Si me piden cierta cantidad de millones, yo se las paso...nos conocemos muchos años. Muy pocas veces hacemos contrato" (Calbuco, julio 2018).

Un aspecto estructuralmente relevante y nítido en las entrevistas a comerciantes es la confianza. Este atributo pareciera ser inherente a las relaciones entre unos y otros, esto aun cuando no son los pescadores quienes la valoran:

Llegaban competidores aquí [a Los Vilos], pero era difícil porque tú tenías una relación de tanto tiempo... llegaba gente a tratar de subir los precios, pero después se iban, entonces la gente no tenía la seguridad de venderle a un tercero... (Edgardo, ex-comerciante de locos, Los Vilos, junio 2018).

Para Jorge se trata incluso de relaciones de amistad, "con cabros que crecieron contigo, todos juntos" (Calbuco, julio 2018). O como lo expresa Jesús, "proveedor" de Calbuco, el soporte de la intermediaciónhabilitación, también hoy, estriba en ese valor inmaterial y colectivo:

Ellos te dicen, viejito quiero salir a la pega, pero necesito malla o necesito cincuenta lucas o ciento cincuenta lucas..., pero eso también es un tema de confianza de años... o sea yo los habilito, yo les paso las platas y ellos generalmente compran petróleo y víveres, y cuando ellos vuelven arreglamos. Es el riesgo que tiene el proveedor y que no quiere correr la empresa (Calbuco, octubre 2017).

Este tipo de visiones contrastan con algunas descripciones declaradas por los pescadores, quienes resaltan cualidades negativas o simplemente instrumentales. Por ejemplo, un dirigente de Pureo (Calbuco) nos comenta que para ellos el intermediario que habilita "es como un ladrón a la vista, tú sabes que... te va a robar y no tienen vergüenza para hacer lo que hacen. Son gente que trabajan pero a costilla de los pescadores" (Pureo, agosto 2017). 
Observamos que esta desigualdad estructural implica un tipo de estratificación a nivel local, pues el interés por acrecentar las ganancias monetarias deriva en que personas de la propia comunidad alcancen un lugar diferenciado y privilegiado en la economía local, una posición con mayores ingresos y mayor capacidad de incidencia sobre las acciones de otros actores del territorio. En clave neoliberal podría ser un tipo de emprendimiento o la asunción de un riesgo por parte de individuos locales -pescadores, por ejemplo- que intentan lograr una posición en el mercado. Es lo que advertimos en 2006 en Puerto Melinka:

Este año me puse a comprar lo que es erizo, probablemente voy a seguir comprando lo que es la luga... traigo trescientos, cuatrocientos litros de combustible y le reparto a la gente que quiere trabajar conmigo y a la vez le cubro sus necesidades, de un traje, un implemento de buceo, de un apoyo en dinero y ellos me lo pagan a mí en trabajo (Melinka, julio 2006).

La cita corresponde a una entrevista realizada a un dirigente de pescadores artesanales. Interesa porque además de dar cuenta de ese proceso de diferenciación interna, que relacionamos con la disponibilidad de medios materiales (aunque también de medios ideacionales) suplementarios por parte de algunos vecinos de las localidades, también revela cómo los sindicatos de pescadores se transforman a partir de los años 1990 en plataformas de emprendimiento para algunos de sus dirigentes.

De acuerdo con relatos de los propios intermediarioshabilitadores, en prácticamente todos los casos se trata de personas o familias del territorio o de la localidad que desarrollan este oficio. Frecuentemente advertimos la expresión de esa estratificación interna: "Lo que pasa es que mi papá, igual que el papá de Julio, compraba locos en Los Vilos, éramos todos de allá" (Ernesto, Calbuco, julio 2018); "Yo empecé muy chica, por necesidad y porque mi papá trabajaba en esto, en productos de mar... él compraba a los pescadores y vendía a hoteles y restoranes" (Alejandra, Los Vilos, junio 2018). Los pescadores de Los Molinos, en Valdivia, refrendan estas impresiones, al remarcar que son personas de los territorios que han emprendido exitosamente en el negocio de proveer y comprar el producto:

[Los comerciantes] eran de Amargos, eran pescadores. Como tenían lancha tenían esa posibilidad de ir más rápido a Valdivia, juntaron más luquitas así que después hacían de comerciantes... [Pero] viven acá, son gente de aquí del sindicato. Lo que pasa es que el comerciante pasó pellejería, empezó pidiendo plata, de todo. Esas casas cafés que se ven allí arriba... donde hay cinco, seis autos, en esos chaleses, ese es comprador. Hay otro de ellos que tiene como cuatro camiones, más camionetas, casa (Grupo de conversación, Los Molinos, octubre 2017).

Otro aspecto que permite matizar su condición estructural es lo que soluciona la intermediación. Precisamente se trata del enlace con el mercado, que en realidad, en la perspectiva crítico-estructural (Comas d'Argemir 1997), es la "articulación" al mercado (la subordinación al capital y el intercambio desigual). Es relevante señalarlo, porque los pescadores suelen decir que los intermediarios constituyen "un mal necesario" (en el registro más negativo) o "una ayuda" (en la valoración positiva). Citemos nuevamente el espacio conversacional en Los Molinos:

Uno siempre va a pelear con el intermediario, porque siempre se ganan una buena tajada, gana casi igual que uno, pero es necesario, a mí me facilita un montón la vida, cualquier intermediario me facilita la vida. Después uno se pone a pensar: bueno, hace más plata que yo, hace menos esfuerzo, ¿pero qué hago?, si voy a entregar [comerciar] mis cosas al otro lado pierdo de ir a pescar. Es una cosa por otra (Los Molinos, Valdivia, 2017).

Por supuesto que estos procesos de diferenciación social pueden variar de un lugar a otro; no obstante, en distintas épocas pareciera configurarse una dinámica de relaciones entre habilitadores y comunidades que trascienden las operaciones comerciales o económicas evidentes. En este sentido, al tiempo que los habilitadores acumulan capital monetario y bienes para la producción, también acumulan prestigio, reputación y en consecuencia poder. Como señalamos más arriba, no estamos tan lejos aquí, al menos hasta cierto punto, de los grandes hombres de la Melanesia descritos por Sahlins (1979). Quien más quien menos, antes o ahora, o potencialmente en el futuro, todos le deben algo a los habilitadores. Es en este sentido que las deudas no son simplemente 
una cuestión formal y pecuniaria; parafraseando a Mauss (2009), en la obligación de devolver se cuela precisamente la moral, condicionada a su vez por las representaciones sociales locales de los comerciantes; y no olvidemos que esas representaciones también son constitutivas de la materialidad que organiza la vida económica (Godelier 1990). Más allá de los enlaces con el mercado, centrales en toda intermediación, es en la capacidad de habilitar donde estriba el micropoder que define el tipo de relaciones que retratan el intercambio desigual.

\section{La habilitación como posibilidad subyacente en la intermediación}

Hemos señalado que, a partir de una estructuración basal e históricamente configurada (Bourdieu 1980), se despliegan espacial y temporalmente variaciones producidas en contextos particulares. De tal modo que la intermediación es esa estructuración basal, consistente en un agente que, en la perspectiva de Polanyi (2009), enlaza dos procesos económicos sustantivos: la extracción y la distribución. En ese enlace hay una asimetría, una relación de poder, en donde la extracción queda inscrita en un espacio de subordinación respecto de la distribución. Esta subordinación implica que quien distribuye posee algo -fundamental para realizar la extracción de productos que luego serán distribuidos-, algo que es imprescindible. Es eso lo que da lugar a la habilitación. Pero la habilitación, tal como se describe en el apartado anterior, no agota las relaciones de intermediación, en el decurso del tiempo aparecen otras variaciones en donde la habilitación deja de ser una institución central. En este sentido, es oportuno hablar de habilitación parcial o eventual, pero siempre posible de ocurrir. En realidad, la habilitación es un atributo, un recurso de poder (y por ello, no sólo es insumo, víveres o dinero), susceptible de ser movilizado o puesto en práctica por cualquier intermediario y en cualquier momento. Cabe pensarla incluso, a partir de variadas expresiones del capital social, en un gradiente que oscila entre el interés por el lucro individual, por un lado, y la expansión de los beneficios colectivos, por otro. Ciertamente, en este último caso nos alejaríamos de la "reciprocidad negativa" aludida más arriba con Sahlins (1979), para admitir que posiblemente en determinadas situaciones, condicionadas por el parentesco y el territorio, esa reciprocidad se explique mejor en sus formas "generalizada" y "equilibrada"; no obstante, insistiremos, en que las distintas expresiones de la habilitación se encuadran predominantemente en lo que Mauss (2009) llamó "la fría razón del comerciante". Lo anterior no desestima, sin embargo, sus condicionamientos morales.

De acuerdo a nuestros registros, y así lo demuestran estudios recientes en toda Latinoamérica (Alcalá 2011), las economías de pesca artesanal devienen en un proceso de progresiva monetarización. Ello se refleja en que el autosustento ocupa un lugar cada vez más limitado en el sistema productivo local. Esta observación, no obstante, es particularmente atingente al caso chileno, pues en otras latitudes regionales el autoconsumo sigue predominando (Villanueva y Flores 2016). Aun así, es crecientemente importante extraer (producir) para el mercado, tendencia manifiesta en el ámbito de la intermediación, en donde el dinero define los tratos, los acuerdos se basan en precios y los adelantos son principalmente pecuniarios. Posiblemente en contextos de mayor aislamiento y de limitado acceso a los mercados de consumo, la habilitación sigue estando muy presente. Es lo que advertimos en Aisén con la extracción del erizo y recientemente en Magallanes con la centolla, en donde se la define como un arreglo institucional no formal entre armadores y tripulantes, $\mathrm{o}$ bien entre empresarios y pescadores (Nahuelhual et al. 2018).

Por su claridad conceptual, compartimos la descripción que en 2007 nos entregó Andrés, buzo mariscador, quien retrata una faena contemporánea de pesca bentónica en las Guaitecas. Aquí puede advertirse el lugar decisivo del habilitador en ese litoral insular. Sostiene Andrés que una vez completada la captura preacordada, en la misma faena el recibidor "le descuenta el combustible que le haya entregado y pide su vale donde estipula la cantidad de cajas y el precio de la caja en un recibo, firmado por el recibidor para después poder cuadrar las cuentas. Bueno, uno saca todo lo que necesite de la lancha porque... lleva todas las provisiones..., ya sea víveres, combustible o también materiales como los ganchos que se pierden muy fácilmente, los aceites. Todas esas cosas, uno las encarga, y se los cargan al siguiente viaje y se descuentan, se van descontando enseguida" (Melinka, julio 2007).

La lógica de la habilitación es persistente, no desaparece, pero en la mayoría de los contextos declina como figura dominante. La extracción de algas pardas (el huiro) constituye hoy en día una de las principales fuentes de sustento en las economías bentónicas de regiones como Coquimbo y Atacama. De forma parcial, la estructura de habilitación sigue estando presente. 
Por ejemplo, en una entrevista sostenida en octubre de 2017 en Los Vilos, Roberto nos describe cómo circunstancialmente los intermediarios solucionan problemas de insumos y liquidez que no pocas veces deben enfrentar los pescadores:

Comohay genteque pide plata, [elintermediario] le compra las cosas y los tiene amarrados, pero él cree que con eso tiene el [monopolio]. Está obligado a entregar el huiro al que corresponda. [El endeudamiento] es personal. El compadre que le de va a querer vivir endeudado con él, [pero] va a ser personal de él. No es pásame 20 lucas. Es sabes que se me echó a perder el motor, y una pana de un motor no es barata... De repente te sale hasta un palo [un millón] ¿y de adonde?. Tú vas a ir a pedir un préstamo al banco y el banco te que dice hay que evaluar. En cambio con el otro [el intermediario] es: sabes que necesito, toma (Roberto, Los Vilos, octubre 2017).

En la costa valdiviana es muy similar. Es decir, una expresión contemporánea de la intermediación encuentra en la habilitación un recurso estructural al que se recurre eventualmente y que permite el flujo del ciclo de extracción-intercambio, en este caso ilustrada en la pesquería del piure:

Por ejemplo, Pesca en Línea está pagando mil pesos el kilo de piure, [y si, en realidad] está a tres por mil, ellos pagan a mil pesos [también]; pero el comerciante [te dice]: yo igual te pago a mil pesos, pero yo te llevo el combustible a la caleta..., yo te lo traigo aquí, ¿necesitas plata? Ahí tienes plata, [por ejemplo en] los días en que está mala la pesca, que está el tiempo malo, ahí hay plata... Después te la descuentan (Arturo, Los Molinos, enero 2018).

Este micro-retrato coincide con lo señalado por Richard Pollnac quien, a partir de un estudio comparativo de economías de pesca artesanal en diversas regiones del planeta, sostiene que "el carácter variable de los recursos pesqueros a menudo coloca al intermediario en el papel de benefactor de los pescadores, cuando la pesca es reducida, y este papel es reforzado porque cuenta con la posibilidad y la voluntad de otorgar préstamos cuando el mal tiempo o la corrosión destruyen o dañan el equipo de pesca (Pollnac 1995:330).

Efectivamente, la evidencia nos indica que, al menos en los casos analizados, en las formas contemporáneas de intermediación, el principal rasgo podría ser la prevalencia del dinero como eje del arreglo, persistiendo la habilitación como posibilidad latente. Y esa posibilidad solo es realizable por parte del comerciante o intermediario.

\section{Conclusión}

Sostenemos que la habilitación constituye una estructuración basal, cuya condición es la de un modelo relacional altamente relevante en el espacio pesquero-artesanal chileno. La idea de estructuración la asociamos a perspectivas socio-antropológicas (Bourdieu 2000; Giménez 2002; Sahlins 1988), que nos permiten observar las relaciones sociales, aun las más estables, inmersas en procesos de cambio y sujetas al devenir de los acontecimientos históricos. En este marco, constatamos la profundidad temporal de la habilitación situándola, al menos, en el siglo XIX y en espacios económicos -de matriz colonialno siempre vinculados a las economías litorales. De acuerdo con las referencias citadas, la habilitación ha constituido una práctica que permitió, ya sea en épocas coloniales o bien contemporáneas, la explotación de los recursos naturales acudiendo, bajo distintas formas de explotación, a la fuerza de trabajo nativa o local.

Entre los principales conceptos que la definen encontramos los adelantos, la obligación de entregar o devolver, el intercambio desigual, la movilidad espacial, pero también la confianza, las representaciones sociales y en general la subjetividad. Nuestros datos indican que estos rasgos aparecen, con matices e intensidades diversas, en los procesos de habilitación que desde la segunda mitad del siglo XX tuvieron lugaren los espacios de actividad pesquero-artesanal en Chile. Asimismo, proponemos pensar en variaciones de la habilitación en donde se despliegan dichos componentes. Por ejemplo, la habilitación como sistema de provisión de víveres dirigidos tanto a las familias que quedan en tierra como a las cuadrillas o tripulaciones de pesca. O bien como provisión de insumos de trabajo (medios de producción) y víveres, pero también como sistema de adelanto de dinero. Cabe reflexionar, sin embargo, que, a partir de las reseñas etnográficas, el dinero parece situarse tendencialmente en el eje principal de la habilitación, sustituyendo ampliamente la provisión de recursos que 
en la actualidad pueden ser adquiridos directamente por los pescadores y sus familias.

Aun en un marco de notables transformaciones, la habilitación persiste como figura de desigualdad y estratificación en el espacio marino-costero y en la pesca artesanal. No solo reproduce, sino que revela la incrustación de una lógica de intercambio asimétrico profundamente arraigado en un contexto de creciente demanda exportadora e industrial de pesquerías. La habilitación persiste cíclica y circularmente, demostrándose etnográficamente que su superación o ruptura es compleja y tal vez improbable al encontrarse asentada, por un lado, en un diferencial de capitales disponibles para activar las faenas de pesca; y por otro, en la lógica de la actividad pesquera (los pescadores se han especializado en ser extractores, actividad que demanda un alto consumo de energía); y finalmente, porque se encuentra inscrita en las ideaciones y/o representaciones que unos y otros agentes (intermediarios-habilitadores y pescadores) tienen de sí mismos y del espacio económico que habitan. Esto último es, de acuerdo a nuestro planteamiento, lo que termina por consagrar la institucionalización de este orden social (Godelier 1990).

Sostenemos que el modelo de habilitación, explicitado o no en esos términos, favoreció unas dinámicas de movilidad en diversas latitudes de la costa chilena. Esta movilidad se explica, en parte, por el interés en capturar o extraer recursos disponibles en locaciones distantes de los asentamientos costeros; pero, al mismo tiempo, se explica porque la habilitación provee las condiciones logísticas para dicha movilidad. Sin embargo, sería un error suponer que la movilidad en el espacio pesquero artesanal responde linealmente a los factores mencionados. En cierto modo cabe hacer explícito que en la base de estas formas de vida subyace una cultura de la movilidad, en donde el desplazamiento es condición de su historia económica, pero también en cuanto a su visión de mundo y al conjunto de representaciones y significaciones que la estructuran y que, en ese marco, condicionan la apropiación ideo-material que estas comunidades litorales hacen de su ambiente.

El epígrafe de la novela de Juan Rulfo, "Pedro Páramo", no solo homenajea una obra sublime de la literatura latinoamericana, sino que nos permite declarar la transversalidad de la estructura de habilitación en los espacios rurales y costero-rurales latinoamericanos. Tal vez, de forma socialmente persistente, marcando su clave en relaciones de poder recurrentes como improntas coloniales, aun trasmutando en órdenes societales modernos. Puede pensarse que la habilitación es, simultáneamente, estructuración e institucionalización basal del espacio económico tradicional, pero que además cabe interpretar en un orden político local. Insistiremos en representarnos, en determinadas circunstancias, al habilitador-intermediario como actor local que, en parte, nos recuerda al gran hombre melanesio teorizado por Sahlins (1979). Declaramos aquí una pista de investigación a futuro, tal vez una hipótesis de trabajo para desentrañar de forma más holgada la dimensión política de lo que inicialmente hemos conceptuado como estructuración económica. Esto, posiblemente, nos permita visualizar otros espacios en los que se configuran dinamicas relacionales inscritas en lógicas de habilitación; por ejemplo, cooperativas y sindicatos de pescadores, y ciertamente el lugar que en esas relaciones tienen algunos de sus dirigentes.

La deuda que media las relaciones de habilitación -nos arriesgamos a sostenerlo a través de una fórmula paradójica-, lo hace, en el sentido de Mauss, como un hecho social total pero limitado. La habilitación, como hecho empírico o potencial, presupone la posibilidad de concretar sustantivamente el ciclo económico-productivo. En otros términos, lo importante no estriba -materialmente- en proveer, sino (sobre todo en la actualidad) en la posibilidad de hacerlo, de habilitar eventualmente a alguien. Sin la habilitación como estructura en potencia no sería posible la economía pesquero-artesanal o costero-tradicional tal como la conocemos hoy en día y no hubiese sido posible en el curso de los siglos XIX y XX. Parafraseando a Godelier (2014), esto no constituye al conjunto de la sociedad litoral tradicional pero sí permite configurar un orden social y económico-político de notable relevancia.

Agradecimientos: Este artículo fue realizado en el marco del proyecto Fondecyt Regular N ${ }^{\circ} 1171309$ : "Condicionamientos socio-ambientales y económicoculturales de la producción y la intermediación en el espacio pesquero artesanal chileno. Una investigación antropológica sobre los límites de la transformación social". Magdalena Navarro agradece a la Beca Agencia Nacional de Investigación y Desarrollo (ANID)/ Programa de Formación de Capital Humano Avanzado/ Beca Doctorado Nacional 2018 - 21180864. Agradecemos a las/os revisores de Chungara por 
sus observaciones y recomendaciones; a Alberto Harambour, por la generosidad de sus sugerencias; $\mathrm{Al}$ Centro de Investigación en Dinámica de Ecosistemas Marinos de Altas Latitudes (IDEAL) por su apoyo investigativo; y de manera especial a las comunidades costeras de Los Vilos, Valdivia, Calbuco y Las Guaitecas por compartirnos sus memorias, saberes y la cotidianidad de su oficio.

\section{Referencias Citadas}

Aguirre, C., C. Mondaca y W. Muñoz 2018. Desarrollismo y capitalismo en espacios marinos. La industrialización de la pesca en Iquique, norte de Chile. Interciencia 43 (9):611-618.

Alcalá, G. 1999 (ed.). Con el Agua hasta los Aparejos. Pescadores y Pesquerías en El Soconusco, Chiapas. CIESAS-UNICAHCIAD, México DF.

Alcalá, G. 2003. Espacios y Actividades Costeras en Michoacán. Aproximaciones Varias. El Colegio de México, El Colegio de Michoacán y Centro de Investigaciones Científicas y Estudios Superiores de Ensenada, México DF.

Alcalá, G. (ed.) 2011. Pescadores en América Latina y el Caribe: Espacio, Población, Producción y Política. Tomo I, Facultad de Ciencias de la Universidad Nacional Autónoma de México, México DF

Balbi, F. 2008. Sobre la presunta 'lógica interna' de una forma 'no capitalista' de producción: el caso de los pescadores comerciales del delta paranaense entrerriano en la década del 1980. En Calando la Vida: Ambiente y Pesca Artesanal en el Delta Entrerriano, editado por M. Boivin, A. Rosato y F. Balbi, pp. 95-136. GIA-PER, Buenos Aires.

Bengoa, J. 2015. Historia Rural del Chile Central. Tomo I. La Construcción del Valle Central. LOM, Santiago.

Boivin, M., A. Rosato y F. Balbi 2008. Calando la Vida: Ambiente y Pesca Artesanal en el Delta Entrerriano. Editorial Antropología Serie Antropología Política y Económica - GIA-PER, Buenos Aires.

Bourdieu, P. 1980. El Sentido Práctico. Taurus, Madrid.

Bourdieu, P. 2000. Las Estructuras Sociales de la Economía Anagrama, Barcelona.

Braudel, F. 1983. Civilization and Capitalism. Vol 2, The wheels of commerce. Harper \& Row, London.

Canales, M. 2006. Metodologías de Investigación Social. LOM, Santiago.

Carneiro, S. 1986. Pescadores do Mar. Ática, São Paulo.

Caro, A. 2018. Calbuco Mariscador: Desarrollo de la Industria Conservera Calbucana entre las Décadas de 1930 y 1980. Tesis para optar al grado de Licenciada en Historia, mención Ciencia Política, Pontificia Universidad Católica de Valparaíso, Facultad de Filosofía y Educación, Instituto de Historia, Valparaíso.

Casement, R. 2012 [1911]. Carta nº 8. Del Cónsul General Casement a sir Edward Grey. En Libro Azul Británico. Informes de Roger Casement y Otras Cartas sobre las Atrocidades en el Putumayo, editado por M. Cornejo y A. Parellada, pp. 44-73. Centro Amazónico de Antropología y Aplicación Práctica y Grupo Internacional de Trabajo sobre Asuntos Indígenas (IWGIA), LimaCopenhague.

Chirif, A. 2017. El caucho, un auge pagado con la vida de miles de indígenas (25 de octubre), en https://www.servindi.org/ actualidad-noticias/25/10/2017/el-caucho-un-auge-pagadocon-la-vida-de-miles-de-indigenas (10 de marzo 2020).
Chirif, A. 2012. El auge del caucho o el juego de las apariencias. En Libro Azul Británico. Informes de Roger Casement y Otras Cartas sobre las Atrocidades en el Putumayo, editado por M. Cornejo y A. Parellada, pp. 8-25. Centro Amazónico de Antropología y Aplicación Práctica y Grupo Internacional de Trabajo sobre Asuntos Indígenas (IWGIA), Lima-Copenhague.

Chonchol, J. 1994. Sistemas Agrarios en América Latina. Fondo de Cultura Económica, Santiago.

Clemente, L. 2009. La Comercialización en Primera Venta de los Productos de la Pesca Marítima Artesanal en el Perú. Problemática y Plan de Mejoras. Centro Tecnológico del Mar -Fundación CETMAR, Pontevedra.

Comas D’ Argemir, D. 1997. Antropología Económica. Ariel, Barcelona.

Cunningham, S. y T. Bostock 2005. Successful Fisheries Management. Issues, Case Studies and Perspectives. Eburon, Delft.

De Grammont, H. 2008. El concepto de nueva ruralidad. En La nueva ruralidad en América Latina. Avances Teóricos y Evidencias Empíricas, editado por E. Pérez, M.A. Farah y H. De Grammont, pp. 23-44. Consejo Latinoamericano de Ciencias Sociales, Pontificia Universidad Javeriana, Bogotá.

Delgado, J.C. 2018. Mi Vieja Caleta. Historia de Unos Viejos Lobos de Mar. Apostrophes, Santiago.

Escobar, A. 2010. Territorios de Diferencia: Lugar, Movimientos, Vida, Redes. Envión, Bogotá.

Ffrench-Davis, R. 2002. Chile, entre el neoliberalismo y el crecimiento con equidad. Revista de Economía Política 22 (4) (88):70-90.

Fuenzalida, A. 2016. El Cabo de la Vida. El Siglo XX Desde el Mar. Ilustre Municipalidad de Los Vilos, Los Vilos.

Galarza, E. y J. Kámiche 2015. Pesca Artesanal: Oportunidades para el Desarrollo Regional. Universidad del Pacífico, Lima.

Giménez, G. 2002. Introducción a la sociología de Pierre Bourdieu. Colección Pedagógica Universitaria 37-38:1-11.

Godelier, M. 1990. Lo Ideal y lo Material. Taurus, Madrid.

Godelier, M. 1998. El Enigma del Don. Paidós, Barcelona.

Godelier, M. 2014. En el Fundamento de las Sociedades Humanas. Lo Que Nos Enseña la Antropología. Amorrortu, Buenos Aires.

Gorgerino, C. 2016. Formas de Organización y Estrategias Productivas de los Pescadores Artesanales de Caleta El Membrillo. Tesis para optar al Grado de Licenciado en Antropología y al Título de Antropólogo Social. Escuela de Antropología, Universidad Academia de Humanismo Cristiano, Santiago.

Gudeman, S. 2000. The Anthropology of Economy: Community, Market, and Culture. Blackwell, Malden.

Gudeman, S. y A. Rivera 1990. Conversations in Colombia: The Domestic Economy in Life and Text. Cambridge University Press, Cambridge. 
Harambour, A. 2019. Soberanías Fronterizas. Estados y Capital en la Colonización de Patagonia (Argentina y Chile, 1830-1922). Ediciones de la Universidad Austral de Chile, Valdivia.

Hobsbawn, E. 2018. ¡Viva la Revolución! Eric Hobswawn Sobre América Latina. Crítica, Barcelona.

Illanes, M.A. 1992. La Dominación Silenciosa. Productores y Prestamistas en la Minería de Atacama. Chile 1830-1860. Instituto Profesional de Estudios Superiores Blas Cañas, Santiago.

Kay, C. 1977. The Latin American hacienda system: ¿Feudal or capitalist? Jahrbuch für Geschichte Lateinamerikas / Anuario de Historia de América Latina 14:369-377.

Kay, C. 1995. Desarrollo rural y cuestiones agrarias en la América Latina contemporánea. Agricultura y Sociedad 75:21-82.

Llagostera, A. 1993. La navegación prehispánica en el norte de Chile: bioindicadores e inferencias teóricas. Chungara Revista de Antropología Chilena 24-25:37-51.

Marín, G. 2003. La pesca en la costa de Michoacán: una visión de conjunto. En Espacios y Actividades Costeras en Michoacán. Aproximaciones Varias, editado por G. Alcalá, pp. 21-68. El Colegio de México, El Colegio de Michoacán y Centro de Investigaciones Científicas y Estudios Superiores de Ensenada, México DF.

Martinic, M. 1986. Nogueira el Pionero. Ediciones de la Universidad de Magallanes, Punta Arenas.

Martinic, M. 2005. De la Trapananda al Aysén: Una Mirada Reflexiva sobre el Acontecer de la Región de Aysén desde la Prehistoria hasta Nuestros Días. Pehuén, Santiago.

Mauss, M. 2009. Ensayo Sobre el Don. Forma y Función del Intercambio en las Sociedades Arcaicas. Katz, Buenos Aires.

Méndez, C. y D. Jackson 2004. Ocupaciones humanas del Holoceno Tardío en Los Vilos (IV región, Chile): origen y características conductuales de la población local de cazadores recolectores de litoral. Chungara Revista de Antropología Chilena 36 (2):279-293.

Mignolo, W. 2003. Historias Locales / Diseños Globales. Colonialidad, Conocimientos Subalternos y Pensamiento Fronterizo. Akal, Madrid.

Montañés, M. 2010. El Grupo de Discusión. Cuadernos CIMAS. Observatorio Internacional de Ciudadanía y Medio Ambiente Sostenible, Madrid.

Morales, D. 2014. El negocio de la Madera: Comerciantes y "Hacheros" de Chiloé, 1850-1875. Magallania 42 (2):41-60.

Morandé, P. 1987. Cultura y Modernización en América Latina. Universidad Católica de Chile, Santiago.

Nahuelhual, L., G. Saavedra, G. Blanco, E. Wesselink, G. Campos y X. Vergara 2018. On super fishers and black capture: Images of illegal fishing in artisanal fisheries of southern Chile. Marine Policy 95:36-45.

Núñez, A.G., R. Molina, E. Aliste y A. Bello 2016. Silencios geográficos de Patagonia-Aysén: territorio, nomadismo y perspectivas para re-pensar los márgenes de la nación en el siglo XIX. Magallania 44 (2):107-130.

Ortiz, P. y A. Chirif 2010. ¿Podemos ser Autónomos? Pueblos Indígenas vs. Estado en Latinoamérica. Intercooperation / RRI, Quito.
Otero, G. 2013. El régimen alimentario neoliberal y su crisis: Estado, agroempresas multinacionales y biotecnología. Antípoda: Revista de Antropología y Arqueología 17:49-78.

Perea, E. 2016. El Ser Proveedor: La Construcción social de la Masculinidad entre los Pescadores de Sisal, Yucatán. Tesis para obtener el título de Licenciado en Desarrollo y Gestión Interculturales, Universidad Nacional Autónoma de México, México DF.

Polanyi, K. 2009. El Sustento del Hombre. Capitán Swing, Madrid.

Pollnac, R. 1995. Las características sociales y culturales del desarrollo pesquero en pequeña escala. En Primero la Gente. Variables Sociológicas en el Desarrollo Rural, compilado por M. Cernea, pp. 305-346. Fondo de Cultura Económica, México DF.

Quiroz, D. y M. Sánchez 2004. Poblamientos iniciales en la costa septentrional de la Araucanía (6500-2000 a.p.). Chungara Revista de Antropología Chilena 36 (Número Especial 1):289-302.

Reyes, O., M. San Román y M. Moraga 2011. Archipiélago de los Chonos: nuevos registros arqueológicos y bioantropológicos en los canales septentrionales. Isla Traiguén, región de Aisén. Magallania 39 (2):293-301.

Rulfo, J. 2015 [1955]. Pedro Páramo. Origo ediciones, Santiago.

Sahlins, M. 1977. Economía de la Edad de Piedra. Akal, Madrid.

Sahlins, M. 1979. Hombre pobre, hombre rico, gran hombre, jefe: Tipos políticos en Melanesia y Polinesia. En Antropología Política, compilado por J.R. Llobera, pp. 267-287. Anagrama, Barcelona.

Sahlins, M. 1988. Islas de Historia: La Muerte del Capitán Cook, Metáfora, Antropología e Historia. Gedisa, Barcelona.

Salas, H. e I. De la Fuente 2013. Nueva ruralidad. Procesos sociolaborales y desagrarización de una sociedad local en México (1980-2010). Gazeta de Antropología 29 (2).

Santoyo, A. 2010. Disputas por el gobierno de indígenas en la antigua comisaría del Vaupés, 1960-1968. Revista Colombiana de Antropología 46 (2):327-352.

Servicio Nacional de Pesca [SERNAPESCA] 2019. Anuario Estadístico de Pesca y Acuicultura 2018. http://www.sernapesca.cl/ informacion-utilidad/anuarios-estadisticos-de-pesca-y-acuicultura.

Simpson, E. 1872. Hidrografía. Esploración de las Costas Occidentales de Patagonia i del Archipiélago de los Chonos, Practicado por orden del Supremo Gobierno en 1871 por el Comandante de Corbeta "Chacabuco", don Enrique M. Simpson. Anales de la Universidad 39:169-197.

Skewes, J.C., R. Álvarezy M. Navarro 2012. Usos consuetudinarios, conflictos actuales y conservación en el borde costero de Chiloé insular. Magallania 40 (1):109-125.

Ther, F. 2012. Antropología del territorio. Polis 11 (32):493-510.

Urbina, X. 2013. Expediciones a las costas de la Patagonia occidental en el período colonial. Magallania 41 (2):51-84.

Urbina, X., O. Reyes y C. Belmar 2020. Canoeros en Chiloé: de facilitadores de las navegaciones españolas en los archipiélagos de los chonos y de guayaneco, a productores y comerciantes, 1567-1792. Chungara Revista de Antropología Chilena 52 (2):335-346. 
Villa, W. 2014. La implementación del Convenio 169 de la OIT en cuanto al desarrollo propio de los pueblos indígenas - El caso de Colombia. En Convenio 169 de la OIT los Desafíos de su Implementación en América Latina a 25 Años de su Aprobación, editado por J. Aylwin y L. Tamburini, pp. 118135. IWGIA, Copenhague.

Villanueva, J. y A. Flores 2016. Contribución de la Pesca Artesanal a la Seguridad Alimentaria, el Empleo Rural y el Ingreso Familiar en Países de América del Sur. Organización de las Naciones Unidas para la Alimentación y la Agricultura (FAO), Santiago.
Villao-Burgos, D., L. Mazón-Arévalo, M. Serrano-Luyó, W. Núñez y L. Núñez-Guale 2017. La comercialización de la pesca artesanal: problemática en los puertos de Anconcito y Santa Rosa provincia de Santa Elena. Revista de Investigaciones Sociales 3 (10):1-11.

Wallerstein, I. 1998. El Capitalismo Histórico. Siglo XXI, México DF.

Wilk, R. 2009. The edge of agency. Routines, habits and volition. En Economies and Cultures: Foundations of Economic Anthropology, editado por R. Wilk y L. Cliggett, pp. 143-154. Westview Press, Boulder.

\section{Notas}

${ }^{1}$ Nuestro énfasis histórico situado a mediados del siglo XIX, no implica desestimar expresiones anteriores. Si bien aquí no exploramos otras temporalidades, habría que mencionar investigaciones históricas en la propia zona sur-austral con alusiones al uso de la fuerza de trabajo indígena que, bajo esquemas similares, sirvió a los intereses de los colonizadores. En particular cabría citar las investigaciones lideradas por Ximena Urbina (Urbina 2013; Urbina et al. 2020).

${ }^{2}$ Por ejemplo, aparejos de pesca, motores, accesorios mecánicos de las embarcaciones, trajes de buceo, compresores, combustible, entre otros.

${ }^{3}$ Comerciantes o transportistas que poseen una autorización o contrato de permisión validado por el estado mexicano, que les permite ejercer dicha actividad.
${ }^{4}$ La asignación por decreto de espacios limitados de mar a las organizaciones de pescadores artesanales (Áreas de Manejo y Explotación de Recursos Bentónicos), contempladas en la Ley General de Pesca y Acuicultura, ha derivado en críticas de parte de las comunidades y sindicatos de pescadores. Entre otros aspectos, porque restringe la movilidad, ya no solo entre regiones, sino también en los espacios locales que históricamente fueron libremente utilizados por buzos y recolectores de orilla.

${ }^{5}$ Una de las expresiones más relevantes de esa articulación estriba en la relación pesca artesanal y pesca industrial, visible, por ejemplo, en la demanda de la industria conservera en el sur austral desde fines del siglo XIX (Caro 2018), o también de la gran industria pesquera en el norte de Chile, donde además hay, desde la segunda mitad del siglo XX, una importante articulación con la fuerza de trabajo artesanal (Aguirre et al. 2018). 
